\title{
Analysis of the Price Change of the Azerbaijani Oil of Azeri Light, using the Monte-Carlo Method in the Conditions of Uncertainty
}

\author{
Nur-Mammadova Nigar \\ Department of "Economics and Management, Azerbaijan State Oil and Industry University, Azerbaijan \\ *Correspondence: Nur-Mammadova Nigar, nurmammadovanigar@gmail.com
}

\begin{abstract}
Purpose: This article examines the uncertain conditions of the oil industry in and post crisis period in Azerbaijan Republic in 2015-2017 and during COVID-19 in 2020.

Design/Methodology: Existing turmoil in the global economy and volatile oil prices affected the economies of the oil-producing countries. Such instability also affected the economy of Azerbaijan Republic and led to a decrease in its key economic indicators, which leads to apply specific methods for identifying risks and estimating its valuation.
\end{abstract}

Findings: The reasons of the sharp drop in oil and oil products demand have been analysed, using the Monte Carlo techniques and with its impact on Azerbaijan Republic as an example.

Practical implications: The author, compiling the forecast for the chosen methodology, clarified forecast for 2018 of oil price of Azerbaijani oil brand Azeri Light in an uncertain environment, and made forecast for coming years, based on these calculations.

Keywords: Oil, Post-crisis oil industry, COVID-19, Forecast, Monte Carlo method

JEL: C1 - Econometric and Statistical Methods and Methodology: General, Q41 - Demand and Supply Prices, F15 - Economic Integration (1), F31 - Foreign Exchange (1)

\section{ARTICLE INFORMATION}

Author(s): Nur-Mammadova Nigar

Received: 02 June, 2021; Accepted: 09 Aug, 2021; Published:16 Aug, 2021 e-ISSN: 2347-4696;

Paper Id: BMN-IJBMR-2021-54;

Citation: doi.org/10.37391/IJBMR.090306

Webpage-link:

https://ijbmr.forexjournal.co.in/archive/volume-9/ijbmr-090306.html

\section{INTRODUCTION}

Oil industry is one of the large-scale economic spheres, which has its own capabilities and rules. In many countries economic stability inside the country has been determined by the situation in the oil market, which, in turn, is influenced by global political and economic factors.

The word "risk" appears first in our thoughts when we speak of industrial and economic activities. The nature of risk varies according to its scope. In each environment, the risk carries with the possibility of both mathematical prediction of an event, with which afterwards decisions are made about budgets, incomes and expenses, as well as the qualitative analysis with the identification of certain factors, methods and types. The essence of the risk is the following elements: the possibility of deviation from any issued solution using alternative options; the reality of the desired result; the likelihood of losses and profits associated with the choice of the right or wrong method or factor.
The main features of risk include inconsistency of nature, alternativeness and uncertainty.

- Inconsistency arises when the objective opinion of one expert meets with the subjective decision of another, and in fact causes this problem to remain in a state of suspension until a certain compromise is revealed.

- Alternativeness - is one of the most applicable, as it gives an opportunity to compensate in case of failure of the basic direction.

- Finally, the whole topic of risk is directly related to uncertainty. According to the book of economist Richard Cantillon ("Essay on the nature of trade in general", 1755) one of the most important functions of risk is its activity in conditions of uncertainty.

In 2020, we came across the driver of global uncertainty, which was COVID-19 virus and, which led to economic shock all over the world. Certainly, such pandemic situation in most cases has short-term economic influence, but it should also be considered to have a significant impact on some areas of economy, as an example to oil industry. This pandemic situation occurred at a time when the oil market was already sensitive and under force. An unexpected decline in oil prices in 2015-2016 and the strong imbalance between supply and demand in the oil market required measures to stabilize discontinuity in the oil market. In January 2016, the lowest price for the "Brent" crude oil, considered the benchmark of 
all world oil prices, was about $\$ 27.88$ per barrel. It was maintained by the Agreement of OPEC and Non-OPEC oilproducing countries (since 2017), and the situation was reached some stabilization, when at the end of 2019 and in the beginning of 2020 a new issue was arisen [1-3].

In general, the most necessary factor for the perfect assessment and managing of the risk - is time. The method that can be considered ideal - is the one that minimizes uncertainty with reducing it to zero, through collected and verified information and calculation. The risk factors themselves, with revealing the nature of their occurrence and activity is a rather complicated process. The foundation of this - the political, economic and financial policies of both individual countries and worldwide.

Studying the economic environment, first appear the indicators, characterizing the dynamics of production, the level of market activity, accumulation, consumption, inflation and the financial condition of the country. This common economic situation reflects not only the internal financial state of the country, but also provides an opportunity to consider the activities of all business areas: heavy (including oil) and light industries, agriculture, and all alike. Through analysis, it is also possible to look at the indicators of raw materials stocks, the value of sales, the level of prices, as well as wages.

Following this logic, in current research, author would like to consider the economic situation, happened in and post-oil crisis, and during the pandemic period of COVID-19 on the example of Azerbaijan Republic.

The article aims to highlight the importance of the "reduction" method of managing the risk, which is being investigated by the author in the oil market of Azerbaijan Republic. By the type of impact, this method can be classified as protective, which allows to avoid financial threats in the future [4-6].

\section{PROCEDURES AND RESEARCH}

The oil industry is one of the main key industries in Azerbaijan Republic, which has its own history since the first oil boom, happened in 19th century. And the second one, happened after signing the "Contact of the Century" in 1994, which connected several oil-producing countries and companies, such as Azerbaijani State Oil Company (SOCAR), BP, Amoco, Statoil, Lukoil, and later Exxon Mobile, Itochu and Inpex. This contract led to export of Azerbaijani oil to European markets, primarily by means of a new main export pipeline to Turkey, generally known as the Baku-TbilisiCeyhan (BTC) pipeline.

After the sudden decline in oil prices in 2015-2016 the minimum price of the Azerbaijani oil of "Azeri Light" brand was observed in January 2016 - \$28.82 per barrel (Figure 1), although the highest oil price was reached to $\$ 149.66$ per barrel in 2008 .

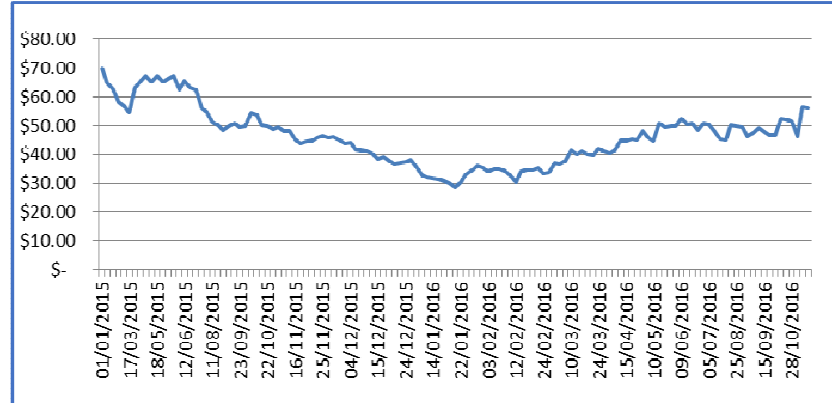

Figure 1: Oil price for Azeri Light brand from Jan, 2015 to Jan, 2016 (Source: author's chart, Excel).

In general, a rash decrease in oil prices negatively affected the economy of Azerbaijan in 2015-2016. The situation was conditioned by the uncertainty in the economic and political environment. This had a critical impact on the activities of the oil companies both in the world and in Azerbaijan Republic during this period in the form of cost savings and cost reduction. When the reserves of the State Oil Fund of the Republic of Azerbaijan (SOFAZ) reached a critical point, the government resorted to a devaluation.

In 2015, the value of Azerbaijan's currency, the New Manat (AZN), fell almost 50\% against dollar. (In Feb 2015 the rate fell from $0.78 \mathrm{AZN}$ to the dollar to $1.05 \mathrm{AZN}$ to dollar, and in December 2015 a further devaluation reduced the rate from $1.05 \mathrm{AZN}$ to the dollar to 1.50 to the dollar). The period after the devaluation - 2016 year- was the most difficult for the country. Azerbaijan was stressed with an actual decline in economic growth for the first time since 1995, with GDP falling $3.1 \%$, while inflation reached to $13 \%$.

However, all these pessimistic consequences became the motivation for the necessary economic reforms, which diversified domestic economy in various spheres of the State. Using certain financial tools, the State managed to keep increasing of the inflation and improve GDP indicators, and to stop the dollarization of the economy. Therefore, by 2017, the number of dollar loans and deposits became noticeably less. After issuing the floating exchange rate, the Azerbaijani Manat was being stabilized to USD at the level of 1.70 [7].

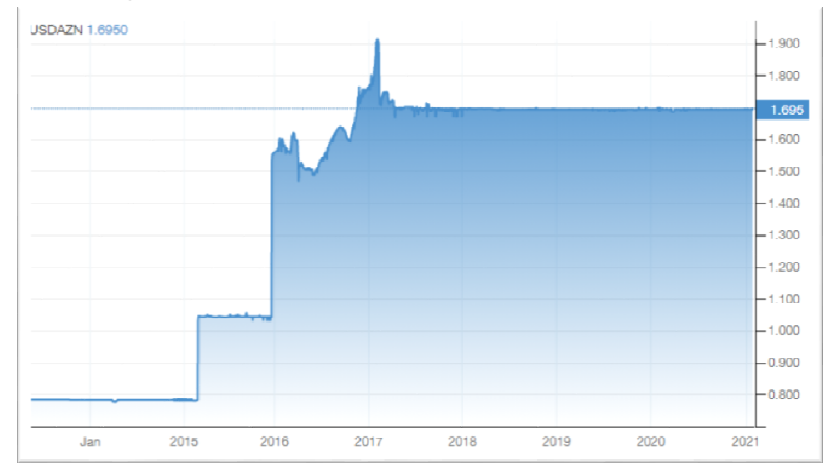

Figure 2: AZN/USD exchange rate, Jan, 2015 to Jan, 2021 (Source: tradingeconomics.com). 
And the Gross Domestic Product (GDP) in Azerbaijan improved to 48.05 billion US dollars in 2019, according to official data from the World Bank, although it was measured to 37.87 billion US dollars in 2016 (Figure 3) [7].

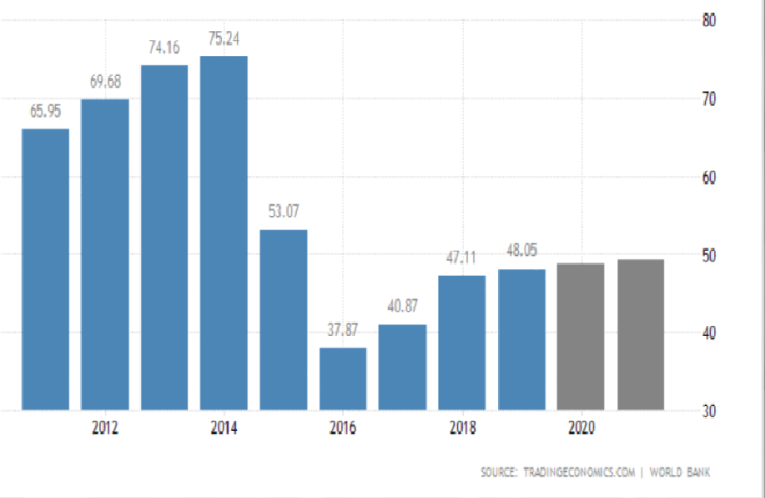

Figure 3: GDP rate for Azerbaijan Republic, Jan, 2012 to Jan, 2019 (Source: tradingeconomics.com).

Oil industry, which plays an important role in the economy of Azerbaijan Republic, in particular plays a vital role in shaping budget forecasts for the upcoming years, and which was severely affected during the "oil crisis", got to build on as well. Thus, in 2015 oil production in Azerbaijan amounted to 41 million 586 thousand tons, whereas in 2016 this figure was set at the level of 41 million 34.5 thousand tons of oil (by $1.3 \%$ less); in 2017 - 38688.9 tons (decrease of $5.7 \%$ compared to 2016); in 2018 - 38814 tons (increase of $0.3 \%$ compared to 2017) and in 2019 - 37500 tons (decrease of $3.4 \%$ compared to 2018) (due to Agreement between OPEC and Non OPEC oil producing countries from 2017 with cutting the oil production. 35 thousand barrel per day for Azerbaijan), according to the data of SOCAR (State Oil Company of Azerbaijan Republic) (Figure 4) [8].

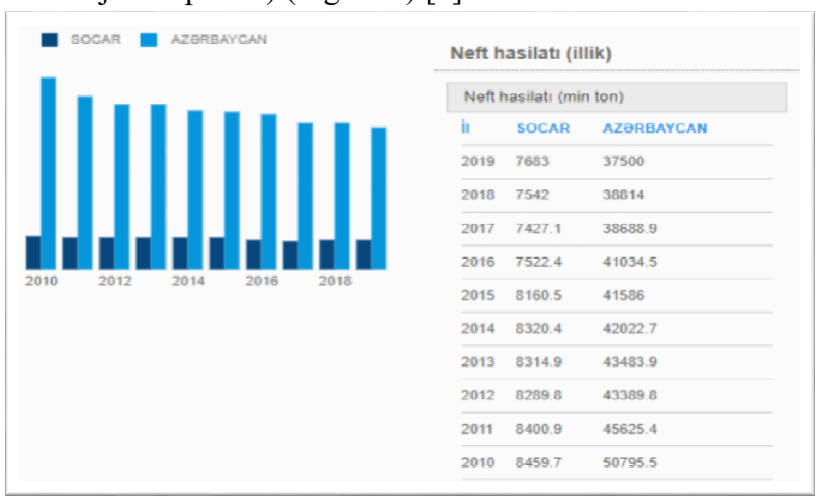

Figure 4: Crude Oil Production, Jan, 2010 to Dec, 2020

(Source: socar.az).

During this period in 2018, a new oilfield "Karabagh" was founded in Azerbaijan as well. It is an offshore oil and gas field in the Caspian Sea in the northern part of Absheron archipelago. A risk service agreement (RSA) for developing the Karabagh field was signed on May 30, 2018, between SOCAR and Equinor (Statoil). The Karabagh oilfield is located 120 kilometers east of Baku, close to the SOCAR operated Shallow Water Gunashli (SWG) field and the BP operated Azeri Chirag Gunashli (ACG) field.

COVID-19 has caused a dramatic change in the industry once more after the stabilized years. And what was troubling issue of COVID-19, in comparing with other such kind of viruses or situations, that it had greater scale - and was more connected among the countries due to travelling. When oil demand began to be fluctuated, OPEC attempted to make a new agreement with Russian Federation to reduce production even more in March 2020. This agreement was failed. The price between Saudi Arabia and Russian Federation was broken, and oil market resulted to be collapsed $[9,10]$.

In April 2020, the lowest price for the "Brent" crude oil, was stated in about $\$ 19.33$ per barrel. And for Azerbaijani oil “Azeri Light" brand in April 2020 it was measured to \$15.81 per barrel (the lowest in Azeri Light brand history).

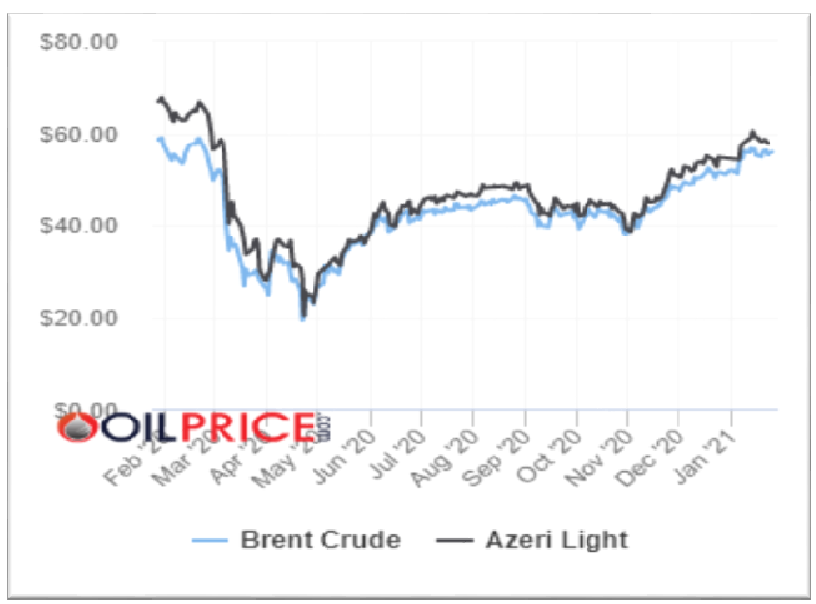

Figure 5: Compared prices Brent/Azeri Light, Feb, 2020 to Jan, 2021 (Source: oilprice.com).

Oil prices fell into pessimistic circumstances, as the spread of COVID-19 to most of the countries, including Azerbaijan, and quarantines were happened in the world. Quarantine and social distancing rules have caused deficit in manufacturing, entertainment, transport sphere and tourism. Almost all huge and small businesses were closed, people stopped travelling, so the demand for oil and oil products remained low for the most part of 2020 .

According to the National Statistics Committee of Azerbaijan Republic GDP for the first three quarters of 2020 was contracted to $4 \%$, comparing to 2019 . In the fourth quarter of 2020 it was reported to $12.35 \%$ compared to 2019 same quarter [1]. 


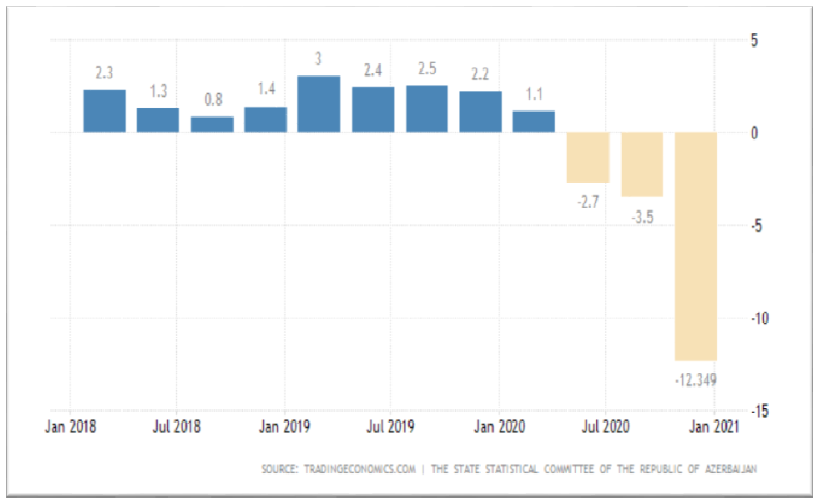

Figure 6: GDP Annual Growth rate for Azerbaijan Republic, Jan, 2018 to Jan, 2021 (Source: tradingeconomics.com).

However, it should be indicated that the correct financial policy of the Government at such a critical point led to avoid the third devaluation of the national currency, as $90 \%$ of budget income referred to oil production and export. It was remained 1.70 AZN to the dollar (Figure 2) [7].

\section{ANALYSIS AND RESULTS}

Gathering of information is one of the key points in calculating, assessing and managing risks. There are two main types of assessing of risks: qualitative and quantitative. It should be emphasized that these are not two different directions, but a phenomenon that goes from one state to another, and as a result of qualitative analysis becomes the starting point for quantitative. Analysing risks, primarily internal and external factors are being considered, which become the causes of a decrease or increase in certain types of risk. Then, one of the approaches, the purpose of which is to determine how sensitive the system is to this or that type of risk, is being used. Having established the necessary level, it is being turned to a qualitative analysis, and in the end the work is being completed with a quantitative analysis, deriving the necessary formula and method for reducing potential risk.

The effectiveness of a formula or model identified by a mathematical method, and their relevance in making decisions of similar problems, depends on the conclusions of qualitative analysis. This is a kind of business plan, including all the advantages and disadvantages of a future system.

The main objective of the risk management - is financial stability in both short and long term, observing all positive and negative scenario, and the possibility of minimizing these negative effects [11].

Situations, that involving risks, caused by political and economic problems are considered as force majeure. Developing methods for compensating for force majeure situations are extremely difficult, virtually impossible, but it is unreasonable to ignore them as well. This can be seen by noting the world situation from the political and economic side, starting from 2014. The dramatic decline of the oil price has led to a big financial crisis and negative consequences in many oil companies. The internal economic situation in a number of countries, including Azerbaijan, has become crucial. As an example, can be taken the prepared annual budgets of Azerbaijan Republic, which were reformed and changed through 2016 year. The reason for this was the inflated average oil price, that was set by the government of Azerbaijan in the end of 2015 ( $\$ 60$ per barrel) as a forecast for 2016, which did not respond to the world actual situation as a result up to $\$ 30-35$ per barrel. The opposite situation began to be observed in 2016: the fixed forecast price of the government for oil in the amount of $\$ 30-35$ per barrel was not again replied to the world - the price of oil was observed in the range of \$ 50-52 per barrel (Oct 2016). In both cases, the country suffered losses, first without filling the budget due to the low price of oil, and then not receiving enough money from the sale of Azeri Light brand oil (the price for Oct 2016$\$ 51$ per barrel). For COVID-19 case Azerbaijan had losses in the budget due to quarantine rules, which were followed through all 2020 year. Crude Oil Production was decreased to $653 \mathrm{bbl}$ in Sept 2020 compared to $726 \mathrm{bbl}$ in Oct 2019 [7].

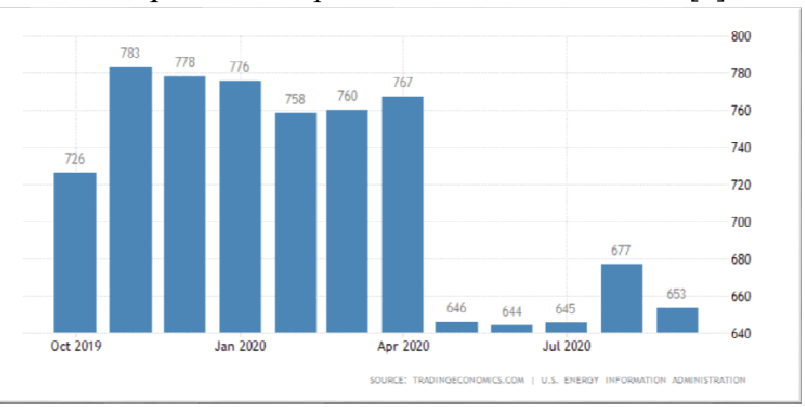

Figure 7: Crude Oil Production for Azerbaijan Republic, Oct, 2019 to Sep, 2020 (Source: tradingeconomics.com).

For the decades, oil industry has been the huge and competitive one, and the main source for income to the budget of the most oil-producing countries. The history of the price changes shows its fluctuations and various kinds of directions in its stabilization. This is what conduct the analysis and forecasts for this industry quite challenging.

There are four distinguished common techniques in risk management: avoidance, reduction, sharing and retention.

Although, the way of solving the problem through risk assessment and mathematical calculation has been judged by many organizations that have used these methods and has not been reliable recently, it is still an essential part for researchers. In addition, it should be mentioned that the oil sector is more defined than others with a high degree of uncertainty due to the constant geopolitical influence [12].

Therefore, the author of the article developed its own appreciation of forecasts using the Monte Carlo method, compiled on the formula of geometric Brownian motion, used in the uncertain conditions.

Monte Carlo simulation can be acknowledged as the generation of random objects or processes by means of a computer. This method, or stochastic modelling, is based on the collection of exponential motions. In contrast with 
historical method, the Monte Carlo method is an accidental continued process, the logarithm of which is a Wiener process (mathematical model of Brownian motion) often used in pricing models. This expression consists of the mathematical expectation and variance.

$$
d S_{t}=S_{t}\left(\mu d t+\sigma d z_{t}\right) d z_{t}
$$

The historical data of any index is taken as a basis, as for instance the price for Azeri Light from 2014 to 2017.

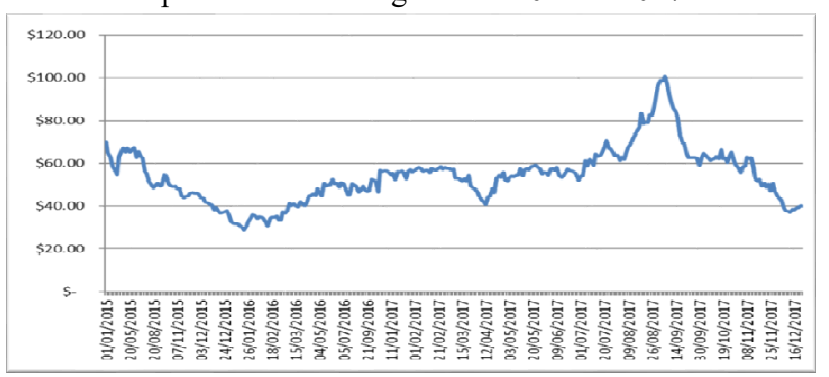

Figure 8: Oil price for Azeri Light brand from Jan, 2015 to Dec, 2017 (Source: author's chart, Excel).

The significance of the Monte Carlo method is to recognize the mathematical expectation of the price, by multiplying the generation of all possible pricing methods. The historical data will be taken as a basis, then will be calculated: $S_{t}-$ the new oil price at the future time $t, S_{0}$ - the fixed price for oil as of a certain date, $\mu$ - the average value or the mathematical expectation expressed in $\%, \sigma$ - the standard deviation expressed in \%, exp (x) - an exponential function, the number $\mathrm{e}(\sim 2.72)$ to the power of $\mathrm{x}$.

The equation can be written in the following discrete form:

$\Delta \mathrm{S}_{\mathrm{t}}=\mathrm{S}_{\mathrm{t}-1}(\mu \Delta \mathrm{t}+\sigma \varepsilon \sqrt{\Delta \mathrm{t}})$

$S_{t+1}-S_{t}+S_{t}\left(\mu \Delta t+\sigma \varepsilon_{1} \sqrt{\Delta t}\right)$

$S_{t+2}=S_{t+1}+S_{t+1}\left(\mu \Delta t+\sigma \varepsilon_{2} \sqrt{\Delta t}\right) S_{T}=S_{t+n}$

... and so on.

The price trajectory is a sequence of pseudo-randomly modelled prices, where a whole series of numbers are appeared, which, if carefully sorted, will be used to determine the average value of the risk range of the oil price. The curve of price formation is a series of irregular generated prices, starting from a given current price and ending with the last one. In case this area consists of equal steps, the random variable will conform with the standard normal distribution. Each such curve is based on the scenario in which the price is set at the last step. The optimal number of steps in the process depends on the length of taken period.

Step-by-step Monte Carlo method works as:
1. According to retrospective data, the mathematical expectation $(\mu)$ and the variance are being calculated.

2. With a random number generator, normally distributed random numbers e $(\exp (\mathrm{x}))$ are generated with the expectation equal to $\mu$ and the standard deviation $(\sigma)$.

3. Random numbers e obtained in the previous step fill in a table of arbitrary dimension (to ensure high accuracy, it must be sufficiently large, for example, 500 columns per 1000 rows).

4. The trajectory of the modelled prices is calculated up to S1000 using the above formula.

If more than 10,000 random iterations are being generated, then the result will be as close to the truth as possible, though this will take a lot of time and effort. Microsoft Excel, which performs calculations automatically with the help of known commands, such as the generation of random numbers (RAND) under the condition of normal distribution (NORMINV), plays the main role here.

The certain advantage of the Monte Carlo method is that, unlike the historical modelling, it allows to consider not a single price trajectory (scenario), but promptly many, which as a rule, improves the accuracy of estimates. There is also a disadvantage of this technique as it gives low accuracy for really short period of time (example couple of months).

Below is a comparison of oil price for Azeri Light brand from Jan 2015 (historical data as basis) to Dec 2018 (as forecast), done by Monte Carlo estimation and the actual prices of Azeri Light brand, taken from the site of Azerbaijan State Oil Company SOCAR.

\begin{tabular}{l|l|l|}
\hline $\begin{array}{l}\text { Level Analysis of author forecast } \\
(27.03 .2017-27.11 .2018)\end{array}$ & $\begin{array}{l}\text { Real price analysis } \\
(27.03 .2017 \\
27.11 .2018)\end{array}$ \\
\hline Mean & $\$ 70.07$ & 65.94 \\
\hline Median & $\$ 69.77$ & 66.17 \\
\hline Min & $\$ 48.25$ & 46.01 \\
\hline Max & $\$ 94.26$ & 87.51 \\
\hline
\end{tabular}

Table 1: Oil price for Azeri Light brand calculations, 20172018.

There are lots of quantitative problems in science, engineering, and finance that are solved in nowadays through Monte Carlo techniques.

These techniques are especially adequate in resolving problems, involving some various sources of uncertainty. The Monte Carlo Method has also demonstrated to be particularly useful in the analysis of the risk of large portfolios of financial products. A great advantage of Monte Carlo techniques for risk analysis is that they can be comfortably used to run scenario analysis - and that they are able to be used to compute risk outcomes under number of different model expectations $[11,13-15]$. 


\section{CONCLUSIONS}

The data obtained as the results of these calculations produced positive results. However, it is still under consideration and further steps of checking its relevance in making forecasts for future prices for the oil of "Azeri Light" brand. The author, compiling the forecast for the chosen methodology for the upcoming and subsequent years, taking as example the beginning of 2017, also carried out comparative analyses of the price of the oil of "Azeri Light" brand using the data from local economic websites and from the State Statistics database.

Based on this analysis the total deviation from the data obtained by using the Monte Carlo method is not more than the actual picture. Using the formula arranged for the Monte Carlo analysis, the author settled the maximum price - $\$ 65$ per barrel for the oil of "Azeri Light" brand for 2018, and the minimum price - $\$ 45$ per barrel, which responded positively to the indicators set by the Government of Azerbaijan in late 2017. The average price was set at $\$ 55$ per barrel.

Using the same methodology author done simulations for forecast of Azeri Light price for 2020-2023, taking into consideration the unexpected political and economic situations, as uncertain condition. In 2020 COVID-19 was the issue, which was accepted as the unknown value for analysis.

For 2020 average price was measured to $55 \$$, max price to $80 \$$, min to $40 \$$. It should be indicated that oil prices could be averaged between $\$ 50-60$ per barrel on a both pessimistic and optimistic scenario respectively. These calculations are under consideration and comparing analysis for the current moment.

The Monte Carlo Method goes on to be one of the most useful ways to scientific computing due to its simplicity and general appropriateness. This, in its turn, proves that this expression can be applied in the calculation of risks and corresponds to the set conditions. The main task of the formula is the economic efficiency and pre-notification of possible decline and rise.

\section{REFERENCES}

[1] https://www.stat.gov.az/news/macroeconomy.php?page=1
[2] Zhang, D., Hu, M., Ji, Q. (2020). Financial markets under the global pandemic of COVID-19. Financ Res Lett, 36, 101528.

[3] Narayan, P. K. (2020). Oil price news and COVID-19-Is there any connection? Energy Research Letters, 1(1), 13176.

[4] Blank, I. A. (2005-2006). Financial Risk Management. Russia: Nika Publishing Center. p. 10.

[5] Carol, A. D. (2015). International Energy Markets: Understanding Pricing, Policies, and Profit (2nd Edn.). Tulsa, Oklahoma: PennWell Corporation.

[6] Ali, M., Alam, N., \& Rizvi, S. A. R. (2020). Coronavirus (COVID-19)-An epidemic or pandemic for financial markets. Journal of Behavioral and Experimental Finance, 27, 100341.

[7] https://tradingeconomics.com/azerbaijan/indicators

[8] http://www.socar.az/socar/az/economics-andstatistics/economics-and-statistics/oil-production

[9] Narayan, P. K., Phan, D. H. B., \& Liu, G. (2021). COVID-19 lockdowns, stimulus packages, travel bans, and stock returns. Finance Research Letters, 38, 101732.

[10] Belgacem, A., Creti, A., Guesmi, K., \& Lahiani, A. (2015). Volatility spill overs and macroeconomic announcements: evidence from crude oil markets. Applied Economics, 47(28), 2974-2984.

[11] Francisco, J. P. G. (2017). Financial Risk Management: Identification, Measurement and Management. Switzerland: Springer International Publishing AG. Pp: 41-60.

[12] Huang W., Zheng Y. (2020). COVID-19: Structural changes in the relationship between investor sentiment and crude oil futures price. Energy Research Letters, 1(2), 13685

[13] Tapman, L. N. (2002). Risks in the economy. Russia: Unity Publishing Center. p. 303.

[14] John C. H. (2015). Risk Management and Financial Institutions (4th Edn). Hoboken, New Jersey: John Wiley \& Sons, Inc.

[15] Qin, M., Zhang, Y. C., \& Su, C. W. (2020). The Essential Role of Pandemics: A Fresh Insight into the Oil Market. Energy Research Letters, 1(1).

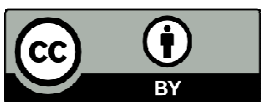

(C) 2021 by the Nur-Mammadova Nigar. Submitted for possible open access publication under the terms and conditions of the Creative Commons Attribution (CC BY) license (http://creativecommons.org/licenses/by/4.0/). 